\title{
Dynamic Nexus Among CO2 Emissions, Fossil Energy Usage and Human Development in East Africa: New Insight From Novel DARDL Simulations
}

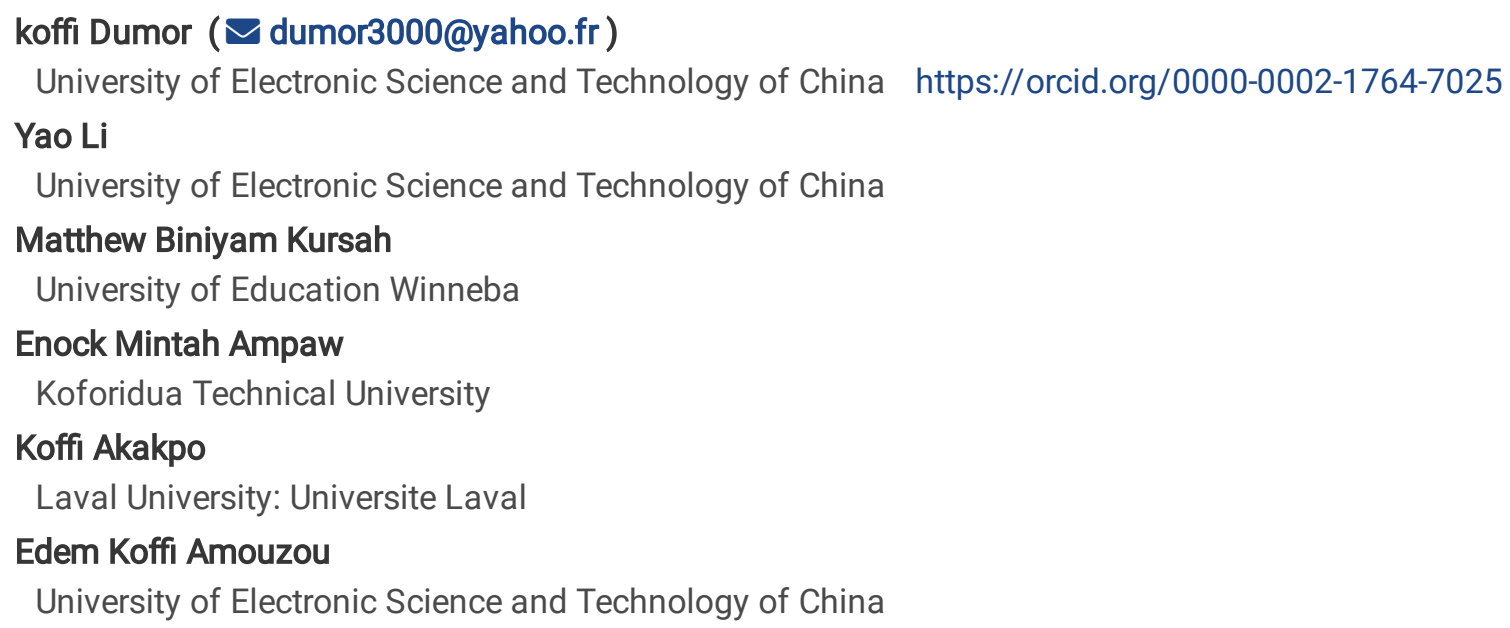




\section{Abstract}

This study investigates the relationship among $\mathrm{CO}_{2}$ emissions, human development index, and fossil energy usage. Essentially, the study was informed by the Sustainable Development Goal 7, which stipulates universal access to renewable and contemporary energy technologies. We employed the novel dynamic autoregressive-distributed lag (DARDL) simulations with a dataset spanning between 1980 and 2020 from East Africa Community (EAC). The study revealed that human development, access to electricity, and trade have a strong correlation with carbon emissions in the long term, whereas fossil energy usage and economic growth have a negative connection with carbon emission. On the other hand, in the short run, human development and fossil energy usage have a positive correlation with carbon emission, while economic growth and foreign direct investment have a negative correlation with carbon emission. Thus, policies that are tailored to enhance the political environment in East Africa are crucial to ensuring realistic access to clean and modern electricity.

\section{Introduction}

Climate change has been a significant issue in recent decades due to the environmental threats associated with it (ICPAC, 2007) and (Sarkodie \& Ozturk, 2020). In addition, global warming has been linked to energy consumption, population growth, humaninduced behavior, and the combustion of fossil fuels (Ouedraogo, 2017) and (Acheampong, Adams, \& Boateng, 2019). Universal effort to combat global warming and its irreparable consequences should, therefore, take an "all hands-on deck" Approach to ensure a greater impact. Thus, a sustained effort would entail global collaboration among established, emerging, and leastdeveloped countries through information sharing, financial support, research, and technology (Jun et al., 2021) and (W.-Z. Wang, Liu, Liao, \& Wei, 2021).

Systematic analyses of the human-nature processes have been inspired by anthropogenic stresses, greenhouse gas (GHG) pollution, and subsequent environmental changes. For example, in environmental economics, the interaction between pollutant pollution, energy usage, and economic growth is a highly debated topic. Thus, industrial development is often cited as a cause of environmental destruction. This was the case in recent studies on carbon dioxide $\left(\mathrm{CO}_{2}\right)$ by (Akbar et al., 2020; Skare and Skare, 2021), and (Jun et al., 2021), which concluded that economic growth induces $\mathrm{CO}_{2}$ emissions by explicitly relating GHG emissions to income level. This view, which is prevalent in the current literature, falls short of describing how the GHG pollution, electricity, and growth nexus works. This paper, therefore, advocates for a reconsideration of the above interaction on a sample of Eastern African Community (EAC) countries.

Africa is predominantly endowed with natural and energy wealth and heavily reliant on the latter. Although an increased understanding of environmental emissions and climate change encourages global attempts to reduce fossil fuel usage, the SSA has seen a steady decrease in renewable energy use over the past two decades (Asongu \& Odhiambo, 2021). Additionally, Africa's electricity production is dominated by coal, oil, and natural gas (Alemzero et al., 2021), the ramifications of which are well known in terms of GHG emissions (Lawson, 2020). Concurrently, growing access to power, life expectancy, and school enrollment were observed (Lawson, 2020) and prompted the issue of whether attempts to improve living standards and human development in Africa ultimately result in fossil fuel usage. Thus, though Africa as a whole is expected to account for approximately $4 \%$ of global $\mathrm{CO}_{2}$ emissions (Lawson, 2020), population development, macroeconomic efficiency, rising access to power, and fossil energy usage jointly imply increased $\mathrm{CO}_{2}$ emissions. Against this schema, we investigate the relationship among energy usage, human development, and $\mathrm{CO}_{2}$ emissions in East African countries by combining GDP, access to power, trade, and direct overseas investment in a unique, multifaceted system for the East African Community (EAC) from 1980 to 2020, as illustrated in Fig. 1. The East Africa region is mainly composed of Kenya, Rwanda, Somalia, South Sudan, Burundi, Djibouti, Eritrea, Ethiopia, Tanzania, and Uganda. The countries in this sub-region are indeed vulnerable to climate variability and extreme weather conditions, such as droughts and flooding. These have left a severe economic and social consequences on the sub-region in some instances.

Given that standard of living is at the heart of any development mechanism, analytical growth measures should be given more weight when studying the association among GHG pollution, electricity, particularly in emerging economies. For instance, in EAC countries like Kenya, Rwanda, and Tanzania, relative wealth coexists with poor education and living standards. This insight may be applied to other Sub-Saharan African countries to highlight the inadequacy of economic expansion as a surrogate for human

Page 2/23 
development in the region. Qualitative measures like per capita GDP and social indicators like education and life expectancy are more reliable proxy estimates of living standards (Shinkevich, Yakunina, \& Klimenko, 2021). Interestingly, suppose the study questions concern long-run mechanisms. In that case, the direction of causality is seldom addressed in current literature (Lawson, Nguyen-Van, \& others, 2021) or the factors that contribute to GHG emissions and the presence of an environmental Kuznets curve (EKC), (Lawson, Martino, \& Nguyen-Van, 2020) and (Liddle, Smyth, \& Zhang, 2020). Even in the African sense, studies that use qualitative indicators of development are uncommon. In addition, the goal of this study is to assess the developmental stage using the Human Development Index (HDI).

This study provided a number of significant contributions. It argues for comprehensive policy decisions on environmental sustainability in East Africa in order to foster a better relationship among the parameters of the study. Second, the study may assist the EAC governments in countering $\mathrm{CO}_{2}$ emissions by elucidating the status of $\mathrm{GHG}$ emissions for remedial measures. The investigation, which is based on the parameters of the study, is the first of its type in the EAC. In contrast to fossil energy use, the study looks at human development to see how it satisfies the mitigation requirements before developing strategies to incorporate further fossil energy usage into the energy mix. A further contribution of this study is the use of (Jordan \& Philips, 2018)'s novel time-series data estimation method. In contrast to previous studies that used analytical time series data tools such as (Pesaran, Shin, \& Smith, 2001) commonly used auto distributive regressive model, this analysis employs a newly established approach, the dynamic ARDL simulation process for the spurious impact of regressors on the predictor variables. It discusses numerous complexities associated with the behavior and perception of the prevalent ARDL model. Finally, this study adds to the expanding body of information on ecological preservation by exploring the widespread association between energy usage and ecological regulations.

The remainder of the paper is organized as follows: The next section reviews the related literature. Section 3 gives a description of the data and the methodology used in the study. Section 4 contains empirical findings and discussions, and Sect. 5 summarizes the key outcomes and provides some policy recommendations based on the empirical findings.

\section{Literature Review}

Following the empirical works of (Essandoh, Islam, \& Kakinaka, 2020) and (Lawson, 2020), a vast body of literature has examined the connection among $\mathrm{CO}_{2}$ pollution, electricity, and Trade. This set of literature emphasizes the causal relationship between these factors and shows that economic development and energy consumption globally induce environmental degradation (Mahmood Ahmad et al., 2021) and (Ansari, Haider, \& Masood, 2021). By focusing on the connection between human development, fossil fuel use, electricity, FDI, and trade in this article, we hope to limit the scope of the literature review to research that employs qualitative indicators of human development. (Gao, Ge, Lu, Wang, \& Zhang, 2021), (Abbasi, Shahbaz, Jiao, \& Tufail, 2021) and (Aslan, Altinoz, \& Özsolak, 2021) present systematic and up-to-date literature reviews of research on economic development.

Apart from economic development, recent analytical studies have cast doubt on the position of qualitative well-being indicators ( $\mathrm{HDI}$, consumption, and literacy rate) in energy usage and GHG emissions. However, quite a significant amount of literature (Acheampong, Erdiaw-Kwasie, \& Abunyewah, 2021) and (Lawson, 2020), have shed light on the relationships between these phenomena. Furthermore, (Lawson, 2020) and (Sarkodie \& Adams, 2020) investigate the correlation among human development, $\mathrm{CO}_{2}$ emission, and energy consumption in the SSA nations and concluded that considerable advances in human development are feasible in Africa via access to energy. For there is a strong correlation between access to electricity and human development. (Acheampong et al., 2021) examined the effect of energy availability on human development across 79 developing countries from 1990 to 2018 by following the pioneering studies of (Acheampong et al., 2021) and (Pata \& Caglar, 2021). Specifically, (Acheampong et al., 2021) used the Lewbel two-stage least squares methodology to illustrate that access to power, and renewable energy promotes human development in the consolidated group.

In comparison, their findings show that while access to power and renewable energy boosts human growth in the Sub-Saharan Africa and Caribbean-Latin America, the reverse was observed in South Asia. Similarly, (Pata \& Caglar, 2021) highlight the critical significance of human capital in reversing environmental pollution in China and that renewable energy alone will not occur to 
address environmental standards. Additionally, the findings indicate that globalization, trade openness, and revenue increase pollution, whereas boosting human assets has a long-term beneficial effect on environmental footprint reduction.

A further aspect of the literature examined the impact of renewable energy usage on social quality of life, given current knowledge of climate challenges and the growing renewable energy usage. In general, no convincing conclusion can be drawn on the importance of renewable energy usage in human development. Based on this assertion, (Cerqueira, Soukiazis, \& Proenca, 2020) and (Ahmad, Muslija, \& Satrovic, 2021) provided evidence for a bidirectional causal association among both renewable energy and HDI. However, (Z. Wang, Bui, Zhang, Nawarathna, \& Mombeuil, 2021) discovered no conclusive findings. Obviously, the area of environmental economics that deals with renewable energy usage and human development requires further exploration.

Similarly, inconclusive findings are evident in the case of environmental pollution and its correlation between energy usage and human development. The current studies on the above subject also indicate that energy usage facilitates human growth but is inconclusive about the effect of $\mathrm{CO}_{2}$ emissions on human health (Cerqueira et al., 2020; Rahman, Zaman, \& Górecki, 2021). On the same topic,(Akbar, Hussain, Akbar, \& Ullah, 2020) demonstrated a causal association between healthcare $\mathrm{costs}_{\mathrm{HDI}} \mathrm{Hand} \mathrm{CO}_{2}$ emissions. More precisely, they demonstrated a bidirectional causal association between healthcare spending and $\mathrm{CO}_{2}$ emissions, implying that $\mathrm{CO}_{2}$ emissions substantially increase healthcare spending in the OECD economies. In conclusion, unlike energy consumption, which has been proven to be causally related to human growth in both directions, the impact of $\mathrm{CO}_{2}$ emissions on human development remains unclear.

In the case of developing countries, especially those in sub-Saharan Africa, studies examining pollutant pollution, energy usage, and development nexus are much more scarce and dearth. (Oluoch, Lal, \& Susaeta, 2021) found positive effects of renewable energy usage on human development in the long term while considering factors such as the literacy rate and life expectancy. Similar findings were seen in (Ouedraogo, 2017)'s study, who examined the correlation and causal relationship among HDI, energy usage, and electricity usage in the Economic Community of West African States(ECOWAS). The findings explicitly indicate that electricity consumption and HDI have a favorable cointegration partnership, suggesting that electricity consumption promotes human growth.

In conclusion, while the controversy about sustainable energy usage and economic growth continues to rage, a body of knowledge demonstrates that energy demand and access to power are critical for human development. These studies are among the few that exist on the relationship among human development, fossil fuel usage, and $\mathrm{CO}_{2}$ emissions. Their outcomes are, however, controversial. None of the studies presented used the hierarchical autoregressive distributed lag framework (Jordan \& Philips, 2018), and none is conducted to East African economies. To address these lacunas in research, the present study emphasizes the function of human development in $\mathrm{CO}_{2}$ emissions in the EAC by investigating the position of access to electricity, international trade, and foreign direct investment (FDI) through the EKC context and application of dynamic ARDL.

\section{Model Specification}

\subsection{Descriptive statistics and variables}

The examination of the connection among $\mathrm{CO}_{2}$ emissions, access to electricity, fossil energy usage, human development (HDI), GDP, FDI, and Trade that have been established in previous studies. As a result, we gathered information on fossil energy consumption, $\mathrm{CO}_{2}$ emissions, access to electricity, $\mathrm{HDI}$, GDP per capita, Trade, and FDI, among other things. However, due to missing values, the final dataset comprises East African countries and is restricted to the timeframe 1980-2020.

Table 1 summarizes the informative figures of the factors used in this study. By contrasting the minimum and maximum values for $\mathrm{CO}_{2}$ emissions, the Human Development Index, access to electricity, fossil energy consumption, GDP, trade, and foreign direct investment (FDI), it is possible to observe disparities, implying a reasonably heterogeneous sample. The Correlation analysis reveals a positive monotonic association between all independent variables and $\mathrm{CO}_{2}$. Correlation analysis reveals a positive monotonic association between all independent variables and $\mathrm{CO}_{2}$. Consequently, prior to performing the econometric analysis, 
the variables are transformed logarithmically to establish a stable variance. Figure 2 depicts the pattern of logarithmically transformed parameters. According to the pattern shown in Fig. 2, the trend happens to rise periodically.

Table 1

Variables Summary Statistics, 1980-2020.

\begin{tabular}{|llllllll|}
\hline Parameter & In CO2 & In HDI & Ln Ener & In GDP & In Elec & Ln FDI & Ln TRD \\
\hline Mean & 1.85 & 1.863 & 1.342 & 1.962 & 1.876 & 1.867 & 1.873 \\
\hline Std. Dev. & 0.226 & 0.205 & 0.22 & 0.216 & 0.217 & 0.214 & 0.212 \\
\hline Max & 2.239 & 2.201 & 1.688 & 2.297 & 2.252 & 2.233 & 2.235 \\
\hline Min & 1.584 & 1.587 & 1.056 & 1.707 & 1.621 & 1.614 & 1.625 \\
\hline Correlation & & & & & & & \\
\hline In CO2 & 1 & & & & & & \\
\hline In HDI & 0.9754 & 1 & & & & & \\
\hline Ln Ener & 0.9759 & 0.9483 & 1 & & & & \\
\hline In GDP & 0.9888 & 0.9952 & 0.9585 & 1 & & & \\
\hline In Elec & 0.9694 & 0.9751 & 0.976 & 0.9886 & 1 & & \\
\hline Ln FDI & 0.9996 & 0.9753 & 0.9747 & 0.9885 & 0.9997 & 1 & \\
\hline Ln TRD & 0.9996 & 0.9754 & 0.9752 & 0.9888 & 0.9997 & 1 & 1 \\
\hline
\end{tabular}

\subsection{Model construction}

The methodological framework of the analysis is adopted from recent literature (Danish \& Ulucak, 2020; Sarkodie et al., 2019) to investigate the relationships among $\mathrm{HDI}$, fossil energy use, GDP, and access to electricity with $\mathrm{CO}_{2}$ emissions. A schematic overview of the test processes is shown in Fig. 3 to improve the flow of the study. This accounted for FDI and trading, and thus, it can be expressed in Eq. (1) as:

$\ln C O_{2}=\lambda_{0}+\chi_{1}\left(\hat{Y}_{t}\right)+\chi_{2} E U_{t}+\chi_{3} H D I_{t}+\chi_{4} \ln E L E C_{t}+\chi_{5} \ln T R A_{t}+\chi_{6} \ln F D I_{t}+\xi_{t}$

Where $t$ is time, $\left(\mathrm{CO}_{2}\right)$ refers to carbon dioxide emissions, $(Y)$ stands for $\mathrm{GDP},\left(E U_{t}\right)$ for fossil energy usage, $\left(E L E C_{t}\right)$ is access to electricity, $\left(F D I_{t}\right)$ is foreign direct investment, $\left(T R A_{t}\right)$ stands for the trade, and $\xi_{t}$ is the remainder term.

The empirical model of the study comprises of the control parameters, FDI, and international trade. Prior researches have shown that both trade and FDI either led to a rise or decline in $\mathrm{CO}_{2}$ emissions. For instance, (Ma, Liu, Ren, \& Jiang, 2019) contended that a growing trade balance adds considerably to $\mathrm{CO}_{2}$ emissions. The magnitude and compositional impacts are anticipated to be positive and extremely substantial. The indirect method impact contributes significantly to air pollution mitigation (Bulus \& Koc, 2021), and Foreign direct investment has a negative effect on the environment (Erdogan, Okumus, \& Guzel, 2020; S. Nathaniel, Aguegboh, Iheonu, Sharma, \& Shah, 2020). The geographic spillover impact of FDI is also negatively connected with air degradation as well (Zhou \& Li, 2021), and (Danish \& Ulucak, 2020) stated that Foreign Direct Investment is a natural pollutant since it transfers polluting technologies and generates air pollution. (Yang, Yang, \& Jia, 2021) discovered that FDI contributes to pollution reduction but does not support the pollution-heaven assumption. The environmental effect of foreign direct investment deteriorates as the volume of its inflows rises. (Y. Wang, Liao, Xu, \& Malik, 2021) argued that FDI is a significant driver in China's carbon emissions and that geographic linkages in emissions occur across 30 provinces. Accordingly, FDI may boost carbon emissions directly or indirectly by boosting energy efficiency. (Zangoei, Salehnia, \& Mashhadi, 2021) demonstrated that FDI may also drive economic development and that economic expansion indirectly affects foreign direct investment. As a consequence, FDI is also anticipated to be negative or positive. 
Trade, additional component included in the framework of the research, has been highly disputed as a possible contributor to $\mathrm{CO}_{2}$ emissions in the literature. Numerous studies have shown that international trade decreases pollution (Acheampong et al., 2019; Zhang, Luo, Yang, \& Li, 2018; Y. Wang et al., 2021) and that cleaner transfer of technology via trading increases energy efficiency and hence decreases $\mathrm{CO}_{2}$ emissions (Q. Wang \& Zhang, 2021). Nevertheless, (Hakimi \& Hamdi, 2020) showed that free trading degrades environmental sustainability. When trade restrictions are lowered, lax environmental standards might emerge from increasing international trade, including the acquisition of polluting technology (Z. Wang \& others, 2019). The impact of Foreign Direct Investment and trading on $\mathrm{CO}_{2}$ emissions is debatable. Thus, the predicted indication might be negative or positive.

\subsection{Econometric Model}

Following the existing literature (Lawson, 2020; Danish \& Ulucak, 2020; Sarkodie, Adams, Owusu, Leirvik, \& Ozturk, 2020, among others), our empirical evidence examines the causal interactions among $\mathrm{CO}_{2}$ emissions, fossil energy, and Human Development Index (HDI) by accounting for GDP, access to electricity, FDI and Trade. To achieve our objective, we specify the novel dynamic ARDL simulations technique, as follows:

$\Delta(\hat{y})_{t}=\lambda_{0}+\vartheta_{0}(\hat{y})_{t-1}+\vartheta_{1}\left(\hat{x}_{1}\right)_{t-1}+\ldots+\vartheta_{k}\left(\hat{x}_{k}\right)_{t-1}+\sum_{i=1}^{r} \lambda_{i} \Delta(\hat{y})_{t-1}+\sum_{j=0}^{s_{1}} \chi_{1 j} \Delta\left(\hat{x}_{1}\right)_{t-j}+\ldots+\sum_{j=0}^{s_{k}} \chi_{k j} \Delta\left(\hat{x}_{k}\right)_{t-j}+\zeta_{t}$

Here $(\hat{y})$ denotes shifts in the output variable, $\left(\lambda_{0}\right)$ is the intercepted, and $t-1$ displays the parameters' higher level of and with lags $S_{k}$ in the first-difference $(\Delta)$ estimator contains the residual term $(\zeta)$ in year $t$. The null hypothesis of no integration $\left[H_{0}=\vartheta_{0}+\vartheta_{1}+\ldots+\vartheta_{k}=0\right]$ against the alternate hypothesis $\left[H_{1}=\vartheta_{0}+\vartheta_{1}+\ldots+\vartheta_{k} \neq 0\right]$ is analyzed. F-value higher than that of the critical value at the upper bound $I(1)$ was assisted by estimated p-values, outcomes in dismissing the null hypothesis of non-cointegration (Kripfganz \& Schneider, 2020). The critical value pathways were employed in the ARDL bound testing approach (Pesaran et al., 2001).

Jordan \& Philips $(2018,2020)$ have implemented a new data series technique, the dynamic ARDL approach, which was posited to operate out and eliminate complexities in preceding ARDL techniques employed to investigate the short-term and long-term link among parameters. This novel approach can predict, boost, and plot to automatically predict dubious variation in the outcome parameter owing to the predictor's parameter, whereas other parameters remain unchanged (Jordan \& Philips, 2018; Sarkodie \& Owusu, 2020). To apply the dynamic simulated ARDL approach, the series of data must be of order one, and the variables under consideration must be cointegrated. The current study satisfies these criteria. It utilizes 5000 iterations of the variables vector, all with joint normal distributions (Sarkodie, Adams, Owusu, et al., 2020).

According to Eq. (1), the error correction model estimation is defined as:

$$
\begin{aligned}
& \Delta \ln \left(C O_{2}\right)_{t}=\lambda_{0} \Delta \ln \left(C O_{2}\right)_{t-1}+\chi_{1} \Delta \ln (\hat{Y})_{t}+\vartheta_{1} \Delta \ln (Y)_{t-1}+\chi_{2} \Delta \ln (E U)_{t}+\vartheta_{2} \Delta \ln (E U)_{t-1}+\chi_{3} \Delta \ln (H D I)_{t} \\
+ & \vartheta_{3} \Delta \ln (H D I)_{t-1}+\chi_{4} \Delta \ln (E L E C)_{t}+\vartheta_{4} \Delta \ln (E L E C)_{t-1}+\chi_{5} \Delta \ln (T R A)_{t}+\vartheta_{5} \Delta \ln (T R A)_{t-1}+\chi_{6} \Delta \ln (F D I)_{t-1}
\end{aligned}
$$

Other techniques, such as ARDL, are included to examine comparative performance in support of dynamic ARDL's methodological contribution. For the current study, the unconstrained error correction form of the ARDL mechanisms can be described as:

$$
\begin{gathered}
\Delta \ln \left(C O_{2}\right)=\lambda_{0}+\lambda_{C O_{2}} \ln \left(C O_{2_{t-1}}\right)+\lambda_{\hat{Y}} \ln \left(\hat{Y}_{t-1}\right)+\lambda_{E U} \ln \left(E U_{t-1}\right)+\lambda_{H D I} \ln \left(H D I_{t-1}\right) \\
+\lambda_{E L E C} \ln \left(E L E C_{t-1}\right)+\lambda_{T R A} \ln \left(T R A_{t-1}\right)+\lambda_{F D I} \ln \left(F D I_{t-1}\right)+\sum_{i=0}^{h^{1}} \delta_{C O_{2}} \ln \left(C O_{2 t-1}\right)+\sum_{i=0}^{h^{2}} \delta_{\hat{Y}} \ln \left(\hat{Y}_{t-1}\right) \\
+\sum_{i=0}^{h^{3}} \delta_{E U} \ln \left(E U_{t-1}\right)+\sum_{i=0}^{h^{4}} \delta_{H D I} \ln \left(H D I_{t-1}\right)+\sum_{i=0}^{h^{5}} \delta_{E L E C} \ln \left(E L E C_{t-1}\right)+\sum_{i=0}^{h^{6}} \delta_{T R A} \ln \left(T R A_{t-1}\right) \\
+\sum_{i=0}^{h^{7}} \delta_{F D I} \ln \left(F D I_{t-1}\right)+\xi_{t}
\end{gathered}
$$




\section{Estimation Results And Discussion}

\subsection{Unit Root}

The central stage in the study process is to establish the initial relations among the parameters to determine the data series sequence. In that regard, the explained parameters must be differentiated at the order I(1). It is not all the explanatory parameters (HDI and fossil energy) that must be stationary or have seasonal unit roots at first-differenced. The results of the Phillip-Perron (PP) and Augmented-DF unit root tests are reported in Table 2. Specifically, Table 2 indicates that the null hypothesis presence of a unit root for the approximation of all the research parameters can be accepted at level one but cannot be accepted at a $5 \%$ significance level at the first difference. Thus, the parameter being studied holds for first-order continuous integration.

Table 2

Unit root test findings

\begin{tabular}{|c|c|c|c|c|}
\hline \multirow[t]{2}{*}{ Data series } & \multicolumn{2}{|c|}{ Phillips-Perron } & \multicolumn{2}{|c|}{ Augmented-DF } \\
\hline & Level & First difference & Level & First difference \\
\hline In_CO2 & 0.359 & $-3.534 \star \star$ & 0.318 & $-3.106 * \star$ \\
\hline In_HDI & 0.786 & $-5.173^{\star \star}$ & 0.723 & $-2.862^{\star \star \star}$ \\
\hline Ln_ENER & 0.499 & $-3.958 \star \star$ & 0.521 & $-3.333^{\star \star}$ \\
\hline In_GDP & 0.309 & -4.516 *ᄎ & -0.51 & 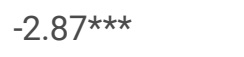 \\
\hline In_ELEC & 0.391 & $-3.484 * \star$ & 0.305 & $-3.063^{\star \star}$ \\
\hline In_FDI & 0.343 & $-3.326 \star \star$ & 0.396 & $-3.022^{\star \star}$ \\
\hline In_TRA & 0.355 & $-3.34^{\star \star}$ & 0.358 & $-3.027 \star \star$ \\
\hline
\end{tabular}

\subsection{Cointegration}

The results of the unit root test suggest that the fundamental parameters are stationary at first order I(1). This, therefore, calls for the integration level of the parameters to be investigated. In keeping with recent studies (Danish \& Ulucak, 2020; Sarkodie, Adams, Owusu, et al., 2020), cointegration between the parameters of interest was examined using the (Pesaran, Shin, \& Smith, 2001)'s ARDL bounds testing technique and Schneider (2018)'s pathways for extreme values endorsed by approximating p-values based on surface outcome regressions. This mechanism is best suited for estimating the lower and upper bound extreme values if the parameters of the study are also integrated of order one, I(1) or order zero, I(0). The asymptotic critical values for any number of long-term forcing parameters and different examples of unconstrained or limited deterministic model components are computed from the regression table. In addition, the surface response predictions record accurate critical values for the unlimited number of short-term factors at the finite sample boundary (Asumadu et al., 2018). The distribution of core attributes is focused on the introduction of more detailed and reliable findings for limited sample sizes.

Table 3 displays the ARDL bounds test to cointegration outcome, which indicates that the F-statistical and t-values of the approximated techniques surpass the upper limit extreme values backed by $p$-values. The conjecture of no cointegration was refuted, hence verifying the cointegration association between the sampled parameters. We may infer cointegration proof for the F-test at the $5 \%$ level since the F-statistic of 5.235 is greater than the I(1) critical value of 4.485 . Nevertheless, the ARDL-bounds ttest fails to reach the critical I(1) threshold. However, we have clear proof of cointegration predicated on the small-sample Fstatistics. This is consistent with the analysis of (Jordan \& Philips, 2018; Sarkodie et al., 2019; Danish \& Ulucak, 2020). 
Table 3

ARDL bound test outcomes

\begin{tabular}{|c|c|c|c|c|c|c|c|c|c|c|}
\hline \multirow[t]{2}{*}{ Predicted model } & \multicolumn{2}{|c|}{ Statistic } & \multicolumn{2}{|l|}{$10 \%$} & \multicolumn{2}{|l|}{$5 \%$} & \multicolumn{2}{|l|}{$1 \%$} & \multicolumn{2}{|c|}{ p-value } \\
\hline & & & $\mathrm{I}(0)$ & $\mathrm{I}(1)$ & $\mathrm{I}(0)$ & $\mathrm{I}(1)$ & $\mathrm{I}(0)$ & $\mathrm{I}(1)$ & $\mathrm{I}(0)$ & $\mathrm{I}(1)$ \\
\hline InCO2 = f (InHDI, InENER, & $\mathrm{F}$ & 5.23 & 2.35 & 3.77 & 2.86 & 4.48 & 4.09 & 6.22 & 0 & 0.02 \\
\hline InGDP, InELEC, InFDI, InTRA) & $\mathrm{t}$ & -3.29 & 2.46 & -3.93 & -2.84 & -4.4 & -3.62 & -5.37 & 0.02 & 0.22 \\
\hline
\end{tabular}

Note that when the F-statistic value exceeds the upper bound, the null hypothesis of no cointegration is refuted; This is also true for the F-value in Table 3, as shown by the P-value.

\subsection{Outcomes of Dynamic stimulated ARDL simulation}

The novel dynamic ARDL simulation proposed by (Jordan \& Philips, 2018) employs a groundbreaking DARD approach in an investigation to address difficulties in current models while analyzing the long and short-term effects in detailed model specifications. The variables used in the dynamic ARDL simulation process must be cointegrated and have an integration order of one. The parameters meet these conditions under consideration in our analysis. Table 4 displays the dynamic ARDL simulation model's long and short-term outcomes. The coefficient on $\ln (\mathrm{HDI})$ is shown to be positive in the long term but statistically insignificant at $5 \%$. The study focuses on the long run and does not go into detail about the short run. This demonstrates that HDI and $\mathrm{CO}_{2}$ emissions are positively correlated. The dominance of the service structure is linked to Africa's economy increasing pollution levels. Fast income growth generates infrastructural investment in clean industries and strengthens environmental regulation demand (Mohmmed et al., 2019). The positive role of industrial economy pollution reduction occurs through structural change in economic development.

The primary energy coefficient is found to be significantly negative, which implies that the efficient usage of fossil energy (coal, oil, and gas) results in $\mathrm{CO}_{2}$ emissions absorption in the distribution channel system. Fossil energy adds to GDP by boosting revenue creation, which keeps the economy afloat without jeopardizing energy requirements for economic sustainability (Solarin, Tiwari, \& Bello, 2019; Nathaniel,2020). The energy demand contributes to economic decarbonization by mitigating pollution created by traditional energy sources and related products(Sarkodie, 2021). Primary energy usage facilitates the energy supply transition to a more reliable internal energy supply and boosts long-term energy sustainability. It also improves the quality of the environment by lowering fossil fuel use and the corresponding resource depletion associated with it, which leads to land usage concerns (Bello \& Solarin, 2021). Primary energy efficiency empowers manufacturers to invest in fossil energy, as increased economic growth generates investment and research, and innovation opportunities in fossil energy. Primary energy usage substitution for fossil fuels could boost the country's growth. This is because fossil fuel is ideal used for heating, transportation, and electricity generation.

Furthermore, primary energy consumption enables societies to fight global warming and climate change while ensuring energy security (Gyamfi, Ozturk, Bein, \& Bekun, 2021; Kucskaya \& Bilgili, 2020). Primary energy consumption is consistent with a lowcarbon development assertion associated with effective pollution-control initiatives. The findings in the present study shed light on the development of renewable energy in Africa, which may aid development without damaging the environment by burning carbon-containing fuels. Therefore, Africa will experience more significant development while simultaneously reducing pollution in the future. African countries should be more critical to addressing their Nationally Determined Contributions (NDCs). They should also advance mechanisms pertaining to carbon reduction projects on the continent (Olubusoye \& Musa, 2020). The findings have been corroborated by Lacour Ayompe et al. (Ayompe, Davis, \& Egoh, 2021) in sub-Saharan Africa, Boqiang Lin and Stephen Agyeman (Lin \& Agyeman, 2021) in sub-Saharan Africa, Sarkodie Samuel Asumadu et al. (Sarkodie, Adams, Owusu, et al., 2020) in China and Etokakpan Udom et al. (Etokakpan, Solarin, Yorucu, Bekun, \& Sarkodie, 2020).

Despite the fact that fossil fuel usage is the principal source of $\mathrm{CO}_{2}$, primary energy consumption and population access to electricity are anticipated to increase $\mathrm{CO}_{2}$ emissions substantially. The findings unequivocally support this view. In other words, the findings demonstrate a significant positive effect of primary energy usage on $\mathrm{CO}_{2}$ emissions, as reported in Table 4. Similar findings arguing for a causal connection between fossil energy usage and $\mathrm{CO}_{2}$ emissions are found in recent contributions 
(Lawson, 2020) and (Sarkodie, 2021). The quest for growth has also contributed to environmental degradation stemming from industrialization in developed and developing countries. The finding revealed that both the long and short-term GDP coefficients are negative and statistically insignificant. This indicates that East African countries have higher institutional quality, conducive to economic efficiency and carbon emission reduction. This is consistent with the works of (Olubusoye \& Musa, 2020), who showed a short-run negative correlation between GDP and carbon emissions in the Middle-Upper income countries. However, this negative short-term impact is transient as a result of the high rate of deforestation and the export of wood logs to generate revenue for economic development. On the contrary, (Asongu, Agboola, Alola, \& Bekun, 2020) in SSA countries and (Adebayo \& Odugbesan, 2020) found a positive effect of GDP on carbon emissions in South Africa.

Additionally, as shown in Table 4, the electricity consumption coefficient is significantly positive in the short term as well as in the long term. This indicates that electricity usage increases environmental degradation, which is in line with (Lawson, 2020) and (Kwakwa, 2021). Also, (Shahbaz, Uddin, Rehman, \& Imran, 2014) corroborate that electricity use results in $\mathrm{CO}_{2}$ emissions and industrialization. Contrary to renewable electricity usage, $\mathrm{CO}_{2}$ emissions. On the contrary to fossil energy use, renewable electricity consumption negatively affects environmental pollution, as demonstrated by (Balsalobre-Lorente, Shahbaz, Roubaud, \& Farhani, 2018) and (Lawson-Lartego, 2020).

In terms of other variables, like foreign direct investment, the outcomes obtained from Table 4 demonstrate that FDI has a negative effect on $\mathrm{CO}_{2}$ emissions but is statistically inconsequential in the short and long run, which is consistent with recent outcomes of (Acheampong et al., 2019). This finding contradicts the outcomes of (Akinlo \& Dada, 2021), who discovered that FDI raises carbon emissions in Sub-Saharan Africa(SSA). Several different scenarios explain these outcomes. Firstly, foreign investors in SSA are predominantly from developed economies with more advanced technologies capable of influencing SSA's energy consumption. As (Balsalobre-Lorente et al., 2018) asserted, energy innovations affect environmental quality intuitively, and their spillover effect in advanced economies would reduce or lessen the extent of $\mathrm{CO}_{2}$ emissions in emerging economies. The second argument is based on the pollution-halo theory, which states that foreign investors leverage the host country's uniform environmental norm to promote greener technologies and lower the number of unfree emissions to the environment. This empirical finding is consistent with the outcomes of (Essandoh et al., 2020) and (Muhammad, Khan, Khan, \& Khan, 2021), who established the role of FDI in reducing environmental degradation. However, it invalidates findings from other developing countries, such as (Sarkodie, Adams, \& Leirvik, 2020) and (Acheampong et al., 2019). Finally, the predicted trade coefficient (InTRD) is positive and statistically insignificant, which is consistent with the recent outcomes of (Acheampong et al., 2019). Thus, international trade contributes to pollution in East African countries level. Furthermore, (Mahmood, Maalel, \& Zarrad, 2019) revealed that trade contributes to $\mathrm{CO}_{2}$ emissions in Tunisia. The positive effect of East African trade may be attributed to the fact that usage imports from the region greatly exceed the export of products and services.

Given that dynamic ARDL is initiated by (Jordan \& Philips, 2018), which is a more advanced variant of ARDL (Pesaran et al., 2001), the present study examined the long and short-term dynamics using the ARDL method for comparative analysis to enhance robust testing. Table 4 displays that HDI impacts on carbon emission are positive and statistically insignificant in both the long and short run. Furthermore, the long-run impacts of fossil energy usage and GDP on $\mathrm{CO}_{2}$ emissions are significantly negative. It is, however, statistically insignificant in the short term. This indicates that both fossil energy usage and GDP contribute to the reduction of carbon dioxide emissions. The coefficient of Electricity is positive and statistically significant in both the long and short term. This suggests that Electricity usage contributes to carbon emissions. The coefficient of FDI is negative but inconsequential in the short and long term. This implies that FDI promotes carbon dioxide emissions. Finally, the effect of trade on carbon footprint is statistically inconsequential and beneficial in the long and short term. Generally, the findings of employing ARDL are consistent with the results of dynamic ARDL. It, therefore, confirms the efficiency and relevance of welldeveloped and policy-relevant results.

Figures (3-8) illustrate the adverse and positive impacts of HDI, fossil fuel usage, GDP, Electricity usage, FDI, and trade in carbon emissions. Specifically, Fig. 3 depicts the positive and negative future shocks of HDI. It suggests that Human development has insignificant positive influence on $\mathrm{CO}_{2}$ emissions in East African economies. These findings are consistent with the empirical outcomes of (Salam \& Noguchi, 2005). Additionally,(Z. Wang, Rasool, Asghar, \& Wang, 2019) conclude that human development can significantly offset environmental challenges and contribute to the region's economic growth. Figures $(4-5)$ provide an 
instinct graph depicting the correlation between energy usage and GDP. The adverse effects of fossil energy usage and carbon emissions endorse the argument that decreasing fossil energy usage would lessen carbon emissions (Lawson, 2020), since a harmful shock is gradually leveled. The long-term strong shock associated with fossil energy usage is constant, despite the fact that it raises $\mathrm{CO}_{2}$ emissions within the short run. The increasing amount of $\mathrm{CO}_{2}$ pollution is consistent with the fact that lifespan emissions from traditional sources of energy are not diminishing (Balsalobre-Lorente et al., 2018).

Figure 5 depicts the impulsive response of economic growth to $\mathrm{CO}_{2}$. A positive shock to economic development reduces $\mathrm{CO}_{2}$ emissions in the long term, but a negative shock raises $\mathrm{CO}_{2}$ emissions. Additionally, (Olubusoye \& Musa, 2020) found that economic expansion had a significant negative effect on short-term carbon emissions in the short term. In contrast,(BalsalobreLorente et al., 2018) indicated that economic growth positively affects carbon emissions. Figure 6 depicts the change in predicted electricity consumption on $\mathrm{CO}_{2}$ emissions. A graphical observation shows that $\mathrm{CO}_{2}$ emissions react positively to a positive shock in electricity usage. However, a negative shock in electricity consumption triggers a negative response in $\mathrm{CO}_{2}$ emissions but stabilizes in the long term. Consistent with similar findings in the EU and Turkey (Balsalobre-Lorente et al., 2018) and (Saint Akadiri, Alola, Olasehinde-Williams, \& Etokakpan, 2020), demonstrated that power consumption exerts a positive impact on $\mathrm{CO}_{2}$ emissions. Equally, Figures (7-8) demonstrate that both negative and positive effects in FDI and world trade lead to improvements in $\mathrm{CO}_{2}$ emissions. 
Table 4

Outcome of Dynamic ARDL

\begin{tabular}{|c|c|c|c|c|}
\hline \multirow[t]{2}{*}{ Predictor variable } & \multicolumn{2}{|c|}{ Dynamic ARDL } & \multicolumn{2}{|l|}{ ARDL } \\
\hline & Coefficient & [prob] & Coefficient & [prob] \\
\hline In HDI & 0.027 & 0.241 & 0.036 & 0.598 \\
\hline d.In HDI & 0.019 & 0.497 & 0.001 & 0.964 \\
\hline In ENER & $-0.016^{\star *}$ & 0.04 & $-0.046^{\star \star \star}$ & 0.052 \\
\hline d.In ENER & 0.009 & 0.486 & $0.026^{\star \star}$ & 0.025 \\
\hline In GDP & -0.050 & 0.141 & -0.121 & 0.247 \\
\hline d.In GDP & -0.030 & 0.397 & 0.025 & 0.565 \\
\hline In ELEC & $0.525^{\star \star}$ & 0.021 & $1.222^{\star \star}$ & 0.000 \\
\hline d.In ELEC & 1.201 ** & 0.000 & $0.697 * \star$ & 0.000 \\
\hline In FDI & -0.287 & 0.159 & -0.433 & 0.310 \\
\hline d.In FDI & -0.494 *夫 & 0.008 & -0.178 & 0.336 \\
\hline In TRD & 0.207 & 0.201 & 0.384 & 0.279 \\
\hline d.In TRD & $0.385^{\star \star}$ & 0.016 & 0.136 & 0.415 \\
\hline Constant & $-0.047^{\star \star}$ & 0.011 & $-0.043^{\star \star}$ & 0.007 \\
\hline$R^{2}$ & 0.9994 & & 0.9994 & \\
\hline Sim & 5000 & & & \\
\hline F-statistic & 1874.43 & 0.000 & 67083.46 & 0.000 \\
\hline \multicolumn{5}{|l|}{ Diagnostic test } \\
\hline Chi2-White's test & 0.98 & 0.691 & 38 & 0.4236 \\
\hline Chi2-Breusch-Godfrey LM & 1.656 & 0.198 & 2.545 & 0.1106 \\
\hline
\end{tabular}

\section{Conclusion And Policy Implications}

This study assesses the links among $\mathrm{HDI}$, energy usage, international trade, and $\mathrm{FDI}$ inflow with $\mathrm{CO}_{2}$ emissions in the background of East African communities (EAC). The study applies the novel dynamic ARDL model to analyze EAC data covering the years 1980 to 2020 . The study demonstrates that human development has a considerable beneficial effect on $\mathrm{CO}_{2}$ emissions, and both electricity usage and trade boost carbon emissions. The usage of fossil energy usage has been discovered to be a renewable energy source that could aid in the decarbonization of the EAC economy. Among other things, international trade adds to $\mathrm{CO}_{2}$ emissions, while FDI does not seem to do so. GDP was identified to have a decreasing beneficial influence on climate change mitigation.

Our analysis shows that attempts to improve human well-being mainly result in primary energy usage in terms of energy factors. Socioeconomic features of the EAC countries, such as access to electricity and trade, are revealed to stimulate energy requirements and, consequently, primary energy consumption in the EAC. On the basis of this, we can conclude that fossil oil usage is driven primarily by energy demand (as a consequence of electricity) and attempts to enhance living standards. This 
conclusion further extends to industrialized countries, whereas fossil fuels offset the increased energy demand from improved well-being.

These findings also have policy implications, such that the EAC governments should spend more on clean energy initiatives, including research and development (RD), to assist the EAC in addressing its severe environmental difficulties. This requires the EAC to make additional efforts toward energy conservation and, more broadly, a move away from conventional and fossil fuelbased energy toward less polluting and sustainable sources. Indeed, the EAC places a premium on human well-being. Nonetheless, if environmental pollution and climate change are not addressed, they will endanger the future of East African Communities. As a result, the EAC countries are urged to address the problem of rising $\mathrm{CO}_{2}$ pollution at their root by encouraging public and private programs as well as massive investments in green energy and energy-efficient technology.

This modeling approach has drawbacks without a doubt, and this article is not different from those with limitations. Due to data constraints, the modeling was unable to quantify the potential advantages of GHG emission reductions, which, therefore, needs further studies. Additionally, beyond the framework of this study, the model should be examined in other regions in order to gain a broader horizon and a comparative historical perspective.

\section{Declarations}

\section{Authors contributions}

The research idea was conceived following a discussion between Koffi Dumor and Yao Li, Edem koffı Amouzou, Koffı Akakpo and Matthew Biniyam Kursah drafted the research plan; Koffı Dumor, Yao Li and Koffı Akakpo Performed the analysis and reported the results; Matthew Biniyam Kursah and Koffı Dumor, drew the figures; Koffı Dumor, Yao Li, Enock Ampaw and Matthew Biniyam Kursah, drafted the manuscript.

Funding Not applicable

\section{Data availability}

The datasets generated during and/or analyzed during the current study are available from the corresponding author on reasonable request.

Ethics approval and consent to participate Not applicable.

Consent for publication Not applicable.

Competing interests The authors declare no competing interests.

\section{References}

1. Abbasi KR, Shahbaz M, Jiao Z, Tufail M (2021) How energy consumption, industrial growth, urbanization, and CO2 emissions affect economic growth in Pakistan? A novel dynamic ARDL simulations approach. Energy 221:119793

2. Acheampong AO, Adams S, Boateng E (2019) Do globalization and renewable energy contribute to carbon emissions mitigation in Sub-Saharan Africa? Sci Total Environ 677:436-446

3. Acheampong AO, Erdiaw-Kwasie MO, Abunyewah M (2021) Does energy accessibility improve human development? Evidence from energy-poor regions. Energy Econ 96:105165

4. Adebayo TS, Odugbesan JA (2020) Modeling CO 2 emissions in South Africa: empirical evidence from ARDL based bounds and wavelet coherence techniques. Environmental Science and Pollution Research, 1-13

5. Ahmad M, Muslija A, Satrovic E (2021) Does economic prosperity lead to environmental sustainability in developing economies? Environmental Kuznets curve theory. Environmental Science and Pollution Research, 1-14

6. Akbar M, Hussain A, Akbar A, Ullah I (2020) The dynamic association between healthcare spending, CO 2 emissions, and human development index in OECD countries: Evidence from panel VAR model. Environment, Development and

Page 12/23 
Sustainability, 1-20

7. Akinlo T, Dada JT (2021) The moderating effect of foreign direct investment on environmental degradation-poverty reduction nexus: evidence from sub-Saharan African countries. Environment, Development and Sustainability, 1-21

8. Alemzero DA, Sun H, Mohsin M, lqbal N, Nadeem M, Vo XV (2021) Assessing energy security in Africa based on multidimensional approach of principal composite analysis. Environ Sci Pollut Res 28(2):2158-2171

9. Ansari MA, Haider S, Masood T (2021) Do renewable energy and globalization enhance ecological footprint: an analysis of top renewable energy countries? Environ Sci Pollut Res 28(6):6719-6732

10. Aslan A, Altinoz B, Özsolak B (2021) The nexus between economic growth, tourism development, energy consumption, and CO 2 emissions in Mediterranean countries. Environ Sci Pollut Res 28(3):3243-3252

11. Asongu SA, Agboola MO, Alola AA, Bekun FV (2020) The criticality of growth, urbanization, electricity and fossil fuel consumption to environment sustainability in Africa. Sci Total Environ 712:136376

12. Asongu SA, Odhiambo NM (2021) Inequality, finance and renewable energy consumption in Sub-Saharan Africa. Renewable Energy 165:678-688

13. Ayompe LM, Davis SJ, Egoh BN (2021) Trends and drivers of African fossil fuel CO2 emissions 1990-2017. Environmental Research Letters 15(12):124039

14. Balsalobre-Lorente D, Shahbaz M, Roubaud D, Farhani S (2018) How economic growth, renewable electricity and natural resources contribute to $\mathrm{CO} 2$ emissions? Energy Policy 113:356-367

15. Bello MO, Solarin SA (2021) Searching for sustainable electricity generation: The possibility of substituting coal and natural gas with clean energy. Energy I\& Environment, 0958305X20985253

16. Bulus GC, Koc S (2021) The effects of FDI and government expenditures on environmental pollution in Korea: The pollution haven hypothesis revisited. Environmental Science and Pollution Research, 1-16

17. Cerqueira PA, Soukiazis E, Proenca S (2020) Assessing the linkages between recycling, renewable energy and sustainable development: evidence from the OECD countries. Environment, Development and Sustainability, 1-26

18. Danish, Ulucak R (2020) Linking biomass energy and CO2 emissions in China using dynamic Autoregressive-Distributed Lag simulations. J Clean Prod 250:119533

19. Erdogan S, Okumus I, Guzel AE (2020) Revisiting the Environmental Kuznets Curve hypothesis in OECD countries: the role of renewable, non-renewable energy, and oil prices. Environ Sci Pollut Res 27(19):23655-23663

20. Essandoh OK, Islam M, Kakinaka M (2020) Linking international trade and foreign direct investment to CO2 emissions: Any differences between developed and developing countries? Sci Total Environ 712:136437

21. Etokakpan MU, Solarin SA, Yorucu V, Bekun FV, Sarkodie SA (2020) Modeling natural gas consumption, capital formation, globalization, $\mathrm{CO} 2$ emissions and economic growth nexus in Malaysia: Fresh evidence from combined cointegration and causality analysis. Energy Strategy Reviews 31:100526

22. Gao C, Ge H, Lu Y, Wang W, Zhang Y (2021) Decoupling of provincial energy-related CO2 emissions from economic growth in China and its convergence from 1995 to 2017. J Clean Prod 297:126627

23. Gyamfi BA, Ozturk I, Bein MA, Bekun FV (2021) An investigation into the anthropogenic effect of biomass energy utilization and economic sustainability on environmental degradation in E7 economies. Biofuels, Bioproducts and Biorefining

24. Hakimi A, Hamdi H (2020) Environmental effects of trade openness: what role do institutions have? Journal of Environmental Economics Policy 9(1):36-56

25. ICPAC I (2007) Climate change and human development in Africa: Assessing the risks and vulnerability of climate change in Kenya, Malawi and Ethiopia. Human Development Report, 2008

26. Jordan S, Philips AQ (2018) Cointegration testing and dynamic simulations of autoregressive distributed lag models. The Stata Journal 18(4):902-923

27. Jordan S, Philips AQ (2020) Exploring meaningful visual effects and quantities of interest from dynamic models through dynamic. Journal of Open Source Software 5(54):2528

Page $13 / 23$ 
28. Jun W, Mughal N, Zhao J, Shabbir MS, Niedbała G, Jain V, Anwar A (2021) Does globalization matter for environmental degradation? Nexus among energy consumption, economic growth, and carbon dioxide emission. Energy Policy 153:112230. https://doi.org/https://doi.org/10.1016/j.enpol.2021.112230

29. Kripfganz S, Schneider DC (2020) Response Surface Regressions for Critical Value Bounds and Approximate p-values in Equilibrium Correction Models 1. Oxford Bull Econ Stat 82(6):1456-1481

30. Kucskaya S, Bilgili F (2020) The wind energy-greenhouse gas nexus: The wavelet-partial wavelet coherence model approach. J Clean Prod 245:118872

31. Kwakwa PA (2021) The carbon dioxide emissions effect of income growth, electricity consumption and electricity power crisis. Management of Environmental Quality: An International Journal

32. Lawson LA (2020) GHG emissions and fossil energy use as consequences of efforts of improving human well-being in Africa. J Environ Manage 273:111136. https://doi.org/https://doi.org/10.1016/j.jenvman.2020.111136

33. Lin B, Agyeman S (2021) Impact of natural gas consumption on sub-Saharan Africa's CO2 emissions: Evidence and policy perspective. Science of The Total Environment 760:143321

34. Ma C-Q, Liu J-L, Ren Y-S, Jiang Y (2019) The Impact of economic growth, FDI and energy intensity on China's manufacturing industry's $\mathrm{CO} 2$ emissions: An empirical study based on the fixed-effect panel quantile regression model. Energies 12(24):4800

35. Mahmood H, Maalel N, Zarrad O (2019) Trade openness and CO2 emissions: Evidence from Tunisia. Sustainability 11(12):3295

36. Mohmmed A, Li Z, Arowolo AO, Su H, Deng X, Najmuddin O, Zhang Y (2019) Driving factors of CO2 emissions and nexus with economic growth, development and human health in the Top Ten emitting countries. Resour Conserv Recycl 148:157-169

37. Muhammad B, Khan MK, Khan MI, Khan S (2021) Impact of foreign direct investment, natural resources, renewable energy consumption, and economic growth on environmental degradation: evidence from BRICS, developing, developed and global countries. Environmental Science and Pollution Research, 1-10

38. Nathaniel S, Aguegboh E, Iheonu C, Sharma G, Shah M (2020) Energy consumption, FDI, and urbanization linkage in coastal Mediterranean countries: re-assessing the pollution haven hypothesis. Environ Sci Pollut Res 27(28):35474-35487

39. Nathaniel SP (2020) Ecological footprint, energy use, trade, and urbanization linkage in Indonesia. GeoJournal, 1-14

40. Olubusoye OE, Musa D (2020) Carbon emissions and economic growth In Africa: Are They Related? Cogent Economics Finance 8(1):1850400

41. Oluoch S, Lal P, Susaeta A (2021) Investigating factors affecting renewable energy consumption: A Panel Data Analysis in Sub Saharan Africa. Environmental Challenges, 100092

42. Ouedraogo NS (2017) Africa energy future: Alternative scenarios and their implications for sustainable development strategies. Energy Policy 106:457-471

43. Pata UK, Caglar AE (2021) Investigating the EKC hypothesis with renewable energy consumption, human capital, globalization, and trade openness for China: Evidence from augmented ARDL approach with a structural break. Energy 216:119220

44. Pesaran MH, Shin Y, Smith RJ (2001) Bounds testing approaches to the analysis of level relationships. J Appl Econom 16(3):289-326

45. Rahman HU, Zaman U, Górecki J (2021) The Role of Energy Consumption, Economic Growth and Globalization in Environmental Degradation: Empirical Evidence from the BRICS Region. Sustainability, 13(4), 1924

46. Saint Akadiri S, Alola AA, Olasehinde-Williams G, Etokakpan MU (2020) The role of electricity consumption, globalization and economic growth in carbon dioxide emissions and its implications for environmental sustainability targets. Science of The Total Environment 708:134653

47. Salam MA, Noguchi T (2005) Impact of human activities on carbon dioxide (CO 2) emissions: A statistical analysis. Environmentalist 25(1):19-30

48. Sarkodie SA (2021) Environmental performance, biocapacity, carbon and ecological footprint of nations: Drivers, trends and mitigation options. Sci Total Environ 751:141912

Page 14/23 
49. Sarkodie SA, Adams S (2020) Electricity access, human development index, governance and income inequality in SubSaharan Africa. Energy Reports 6:455-466

50. Sarkodie SA, Adams S, Leirvik T (2020) Foreign direct investment and renewable energy in climate change mitigation: Does governance matter? J Clean Prod 263:121262. https://doi.org/https://doi.org/10.1016/j.jclepro.2020.121262

51. Sarkodie SA, Adams S, Owusu PA, Leirvik T, Ozturk I (2020) Mitigating degradation and emissions in China: the role of environmental sustainability, human capital and renewable energy. Sci Total Environ 719:137530

52. Sarkodie SA, Owusu PA (2020) How to apply the novel dynamic ARDL simulations (dynardl) and Kernel-based regularized least squares (krls). MethodsX 7:101160

53. Sarkodie SA, Ozturk I (2020) Investigating the environmental Kuznets curve hypothesis in Kenya: a multivariate analysis. Renew Sustain Energy Rev 117:109481

54. Sarkodie SA, Strezov V, Weldekidan H, Asamoah EF, Owusu PA, Doyi INY (2019) Environmental sustainability assessment using dynamic autoregressive-distributed lag simulations-nexus between greenhouse gas emissions, biomass energy, food and economic growth. Sci Total Environ 668:318-332

55. Shahbaz M, Uddin GS, Rehman IU, Imran K (2014) Industrialization, electricity consumption and CO2 emissions in Bangladesh. Renew Sustain Energy Rev 31:575-586

56. Shinkevich A, Yakunina R, Klimenko T (2021) Index Approach Implementation Mechanism to the Human Capital Assessing Within the Framework of the Sustainable Development Concept

57. Solarin SA, Tiwari AK, Bello MO (2019) A multi-country convergence analysis of ecological footprint and its components. Sustainable Cities Society 46:101422

58. Wang Q, Zhang F (2021) The effects of trade openness on decoupling carbon emissions from economic growth-evidence from 182 countries. J Clean Prod 279:123838

59. Wang W-Z, Liu L-C, Liao H, Wei Y-M (2021) Impacts of urbanization on carbon emissions: An empirical analysis from OECD countries. Energy Policy 151:112171

60. Wang Y, Liao M, Xu L, Malik A (2021) The impact of foreign direct investment on China's carbon emissions through energy intensity and emissions trading system. Energy Econ 97:105212

61. Wang Z, Bui Q, Zhang B, Nawarathna CLK, Mombeuil C (2021) The nexus between renewable energy consumption and human development in BRICS countries: The moderating role of public debt. Renewable Energy 165:381-390

62. Wang Z, \& others (2019) Does biomass energy consumption help to control environmental pollution? Evidence from BRICS countries. Science of the Total Environment, 670, 1075-1083

63. Wang Z, Rasool Y, Asghar MM, Wang B (2019) Dynamic linkages among CO 2 emissions, human development, financial development, and globalization: empirical evidence based on PMG long-run panel estimation. Environ Sci Pollut Res 26(36):36248-36263

64. Yang X, Yang Z, Jia Z (2021) Effects of technology spillover on CO2 emissions in China: A threshold analysis. Energy Reports 7:2233-2244

65. Zangoei S, Salehnia N, Mashhadi MK (2021) A comparative study on the effect of alternative and fossil energy consumption on economic growth and foreign direct investment in selected countries using SUR approach. Environ Sci Pollut Res 28(16):19799-19809

66. Zhang L, Luo M, Yang D, Li K (2018) Impacts of trade liberalization on Chinese economy with Belt and Road initiative. Maritime Policy Management 45(3):301-318

67. Zhou A, Li J (2021) Analysis of the spatial effect of outward foreign direct investment on air pollution: evidence from China. Environmental Science and Pollution Research, 1-20

\section{Figures}




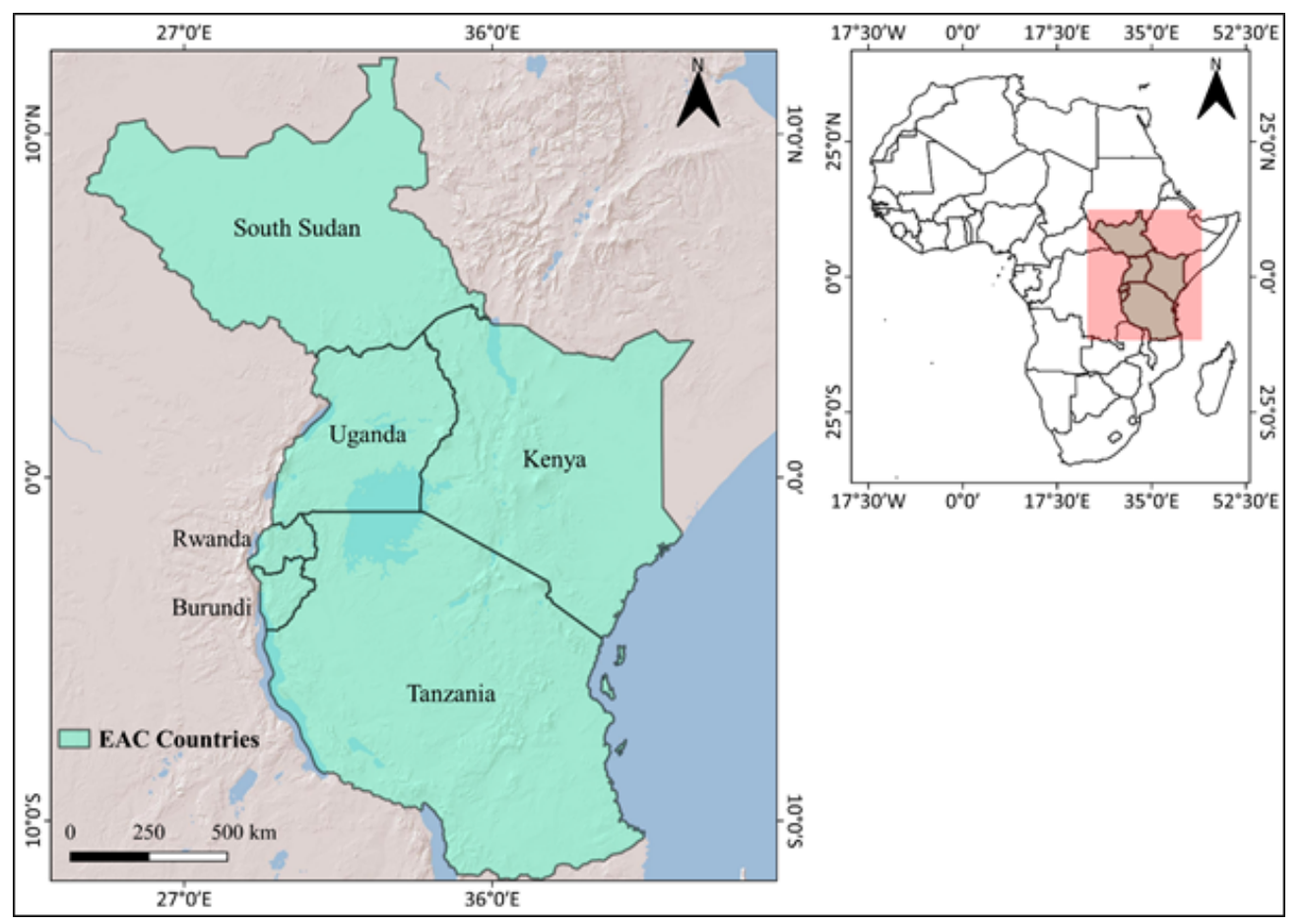

Figure 1

Map of the East African (EAC) Countries 
LNCO2
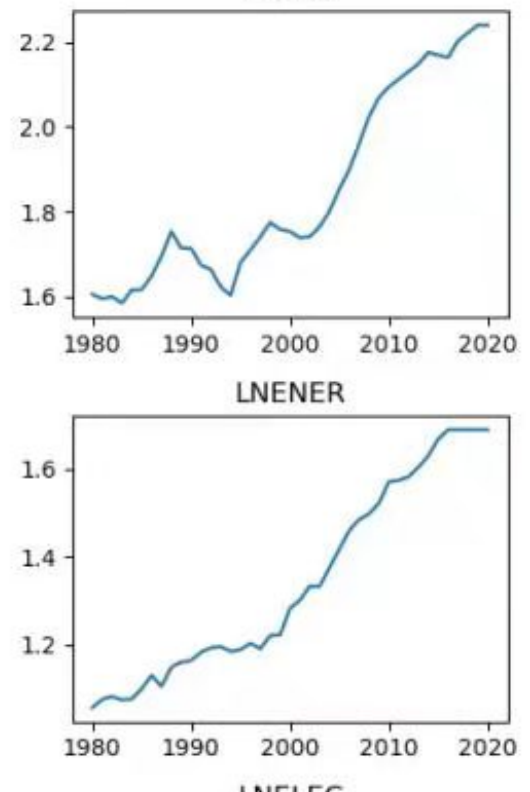

LNELEC
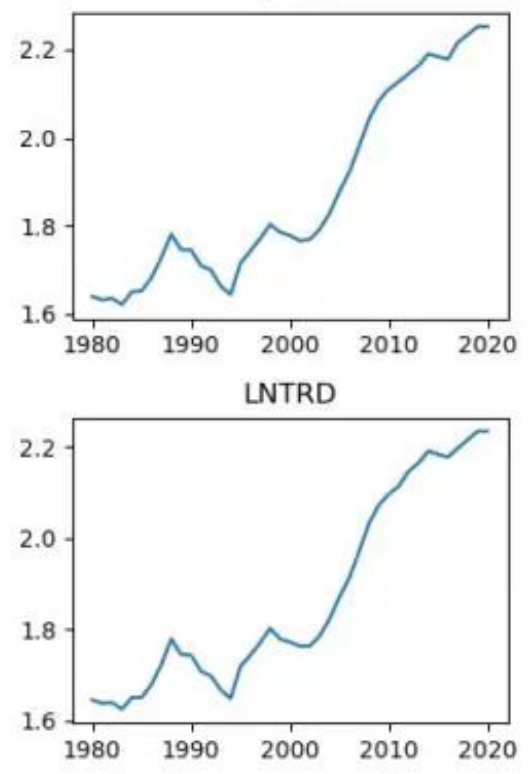

LNHDI
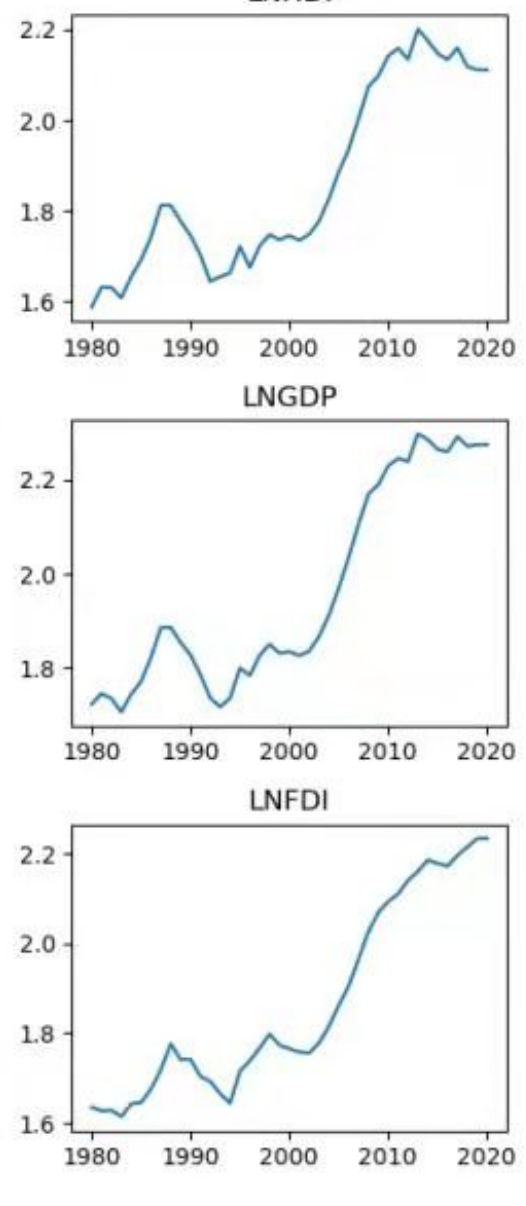

\section{Figure 2}

Trend of variables

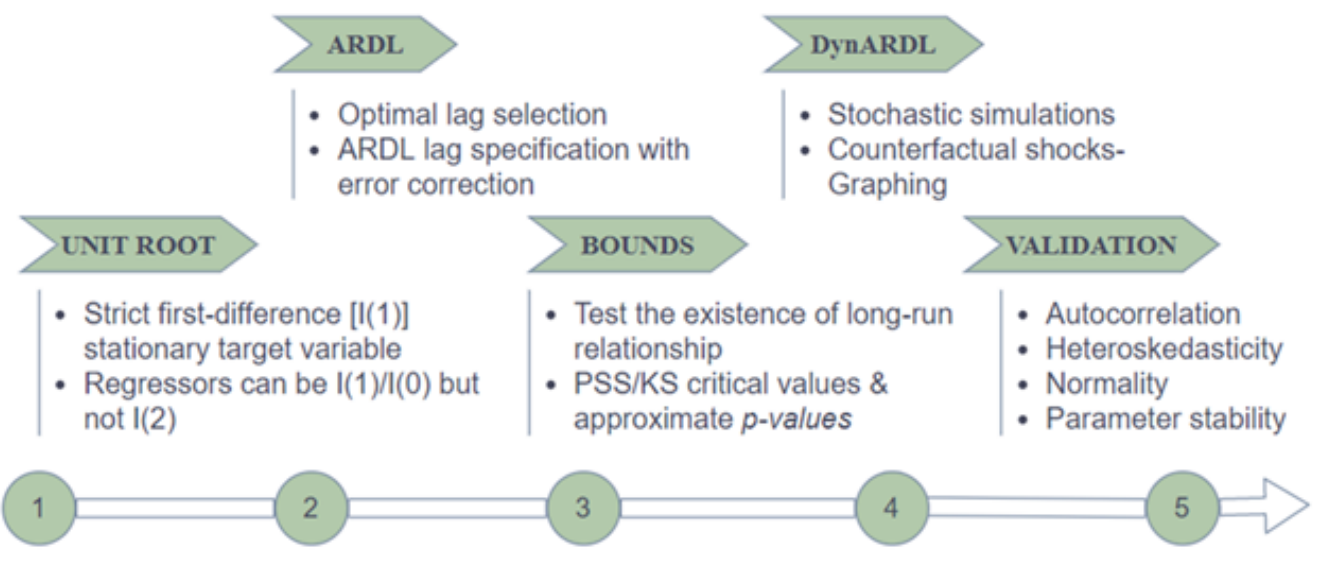

Figure 3 


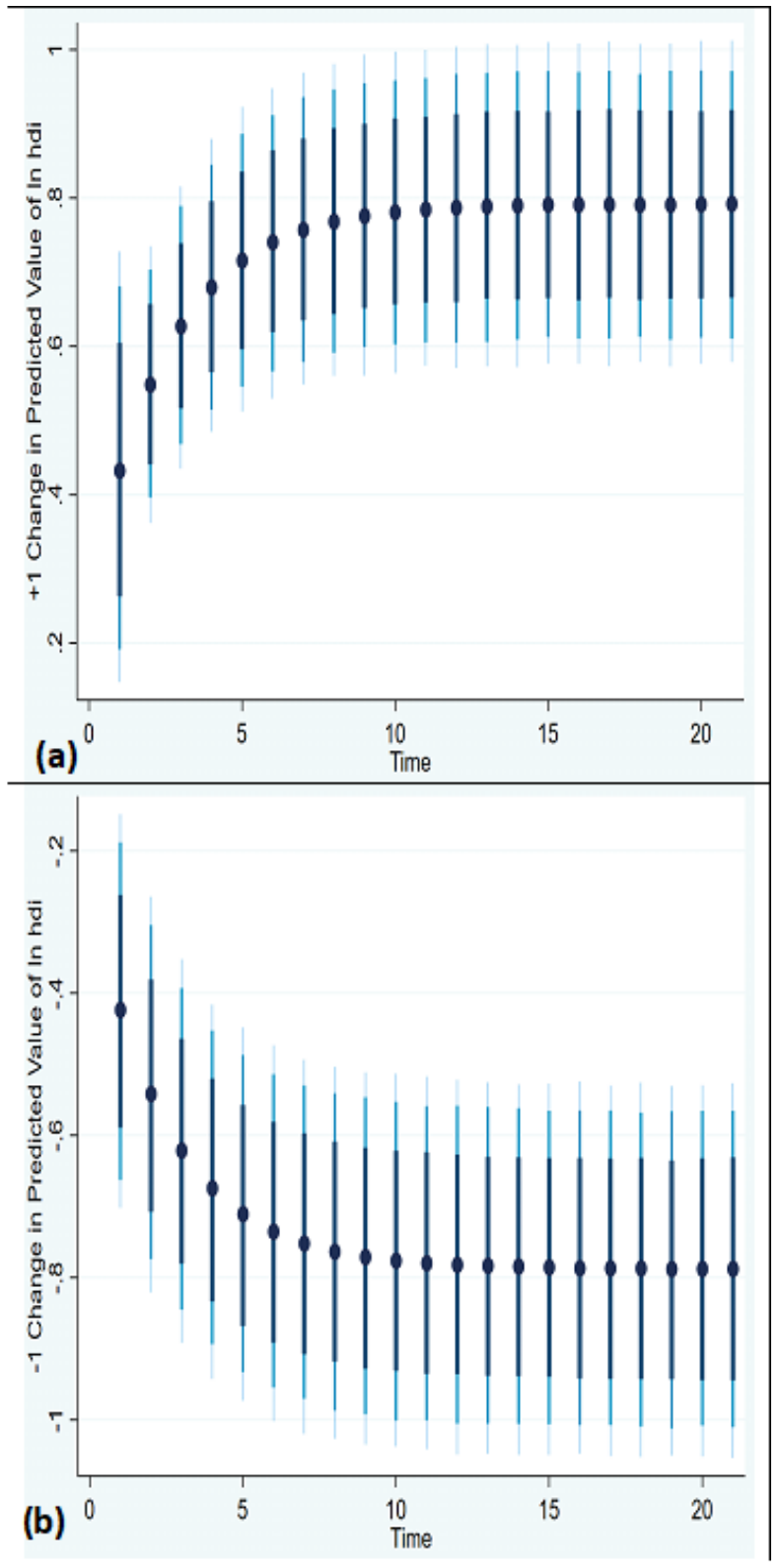

Figure 4

$( \pm 1 \%)$ alterations in predicted $\mathrm{HDI}$ on $\mathrm{CO} 2$ emissions 


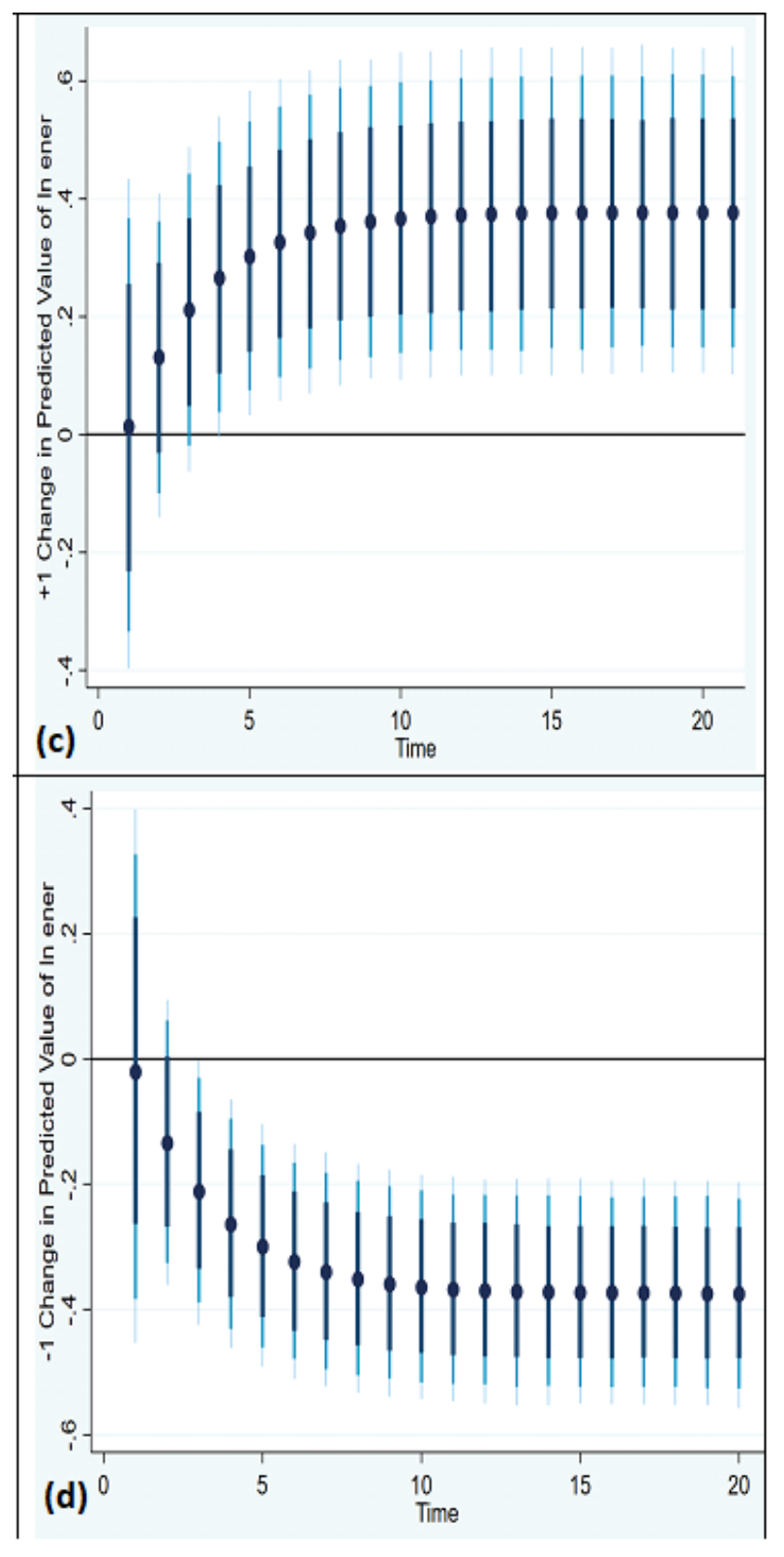

Figure 5

$( \pm 1 \%)$ alterations in predicted Energy use on $\mathrm{CO} 2$ emissions 


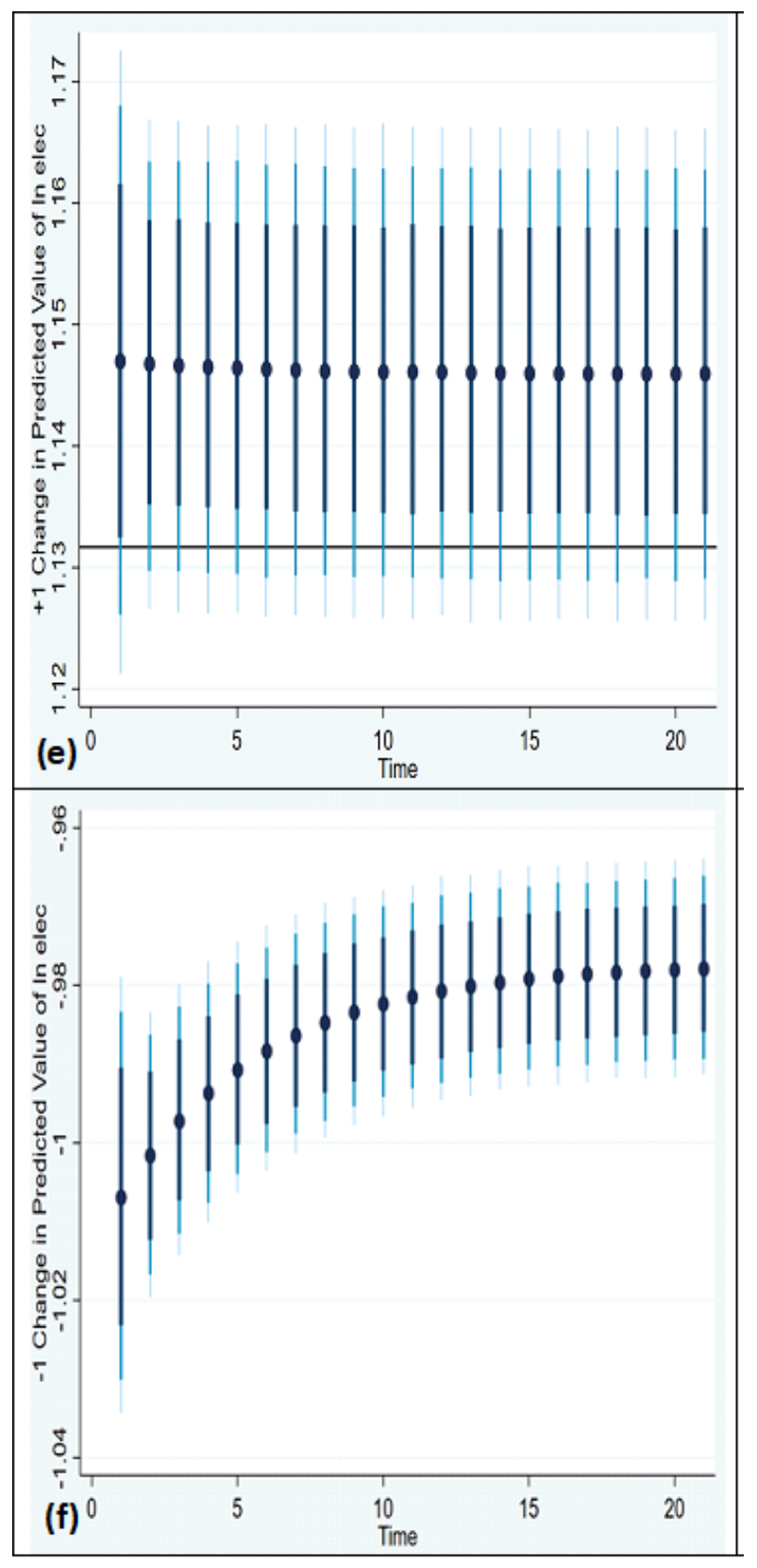

Figure 6

$( \pm 1 \%)$ alterations in predicted Electricity on $\mathrm{CO} 2$ emissions 


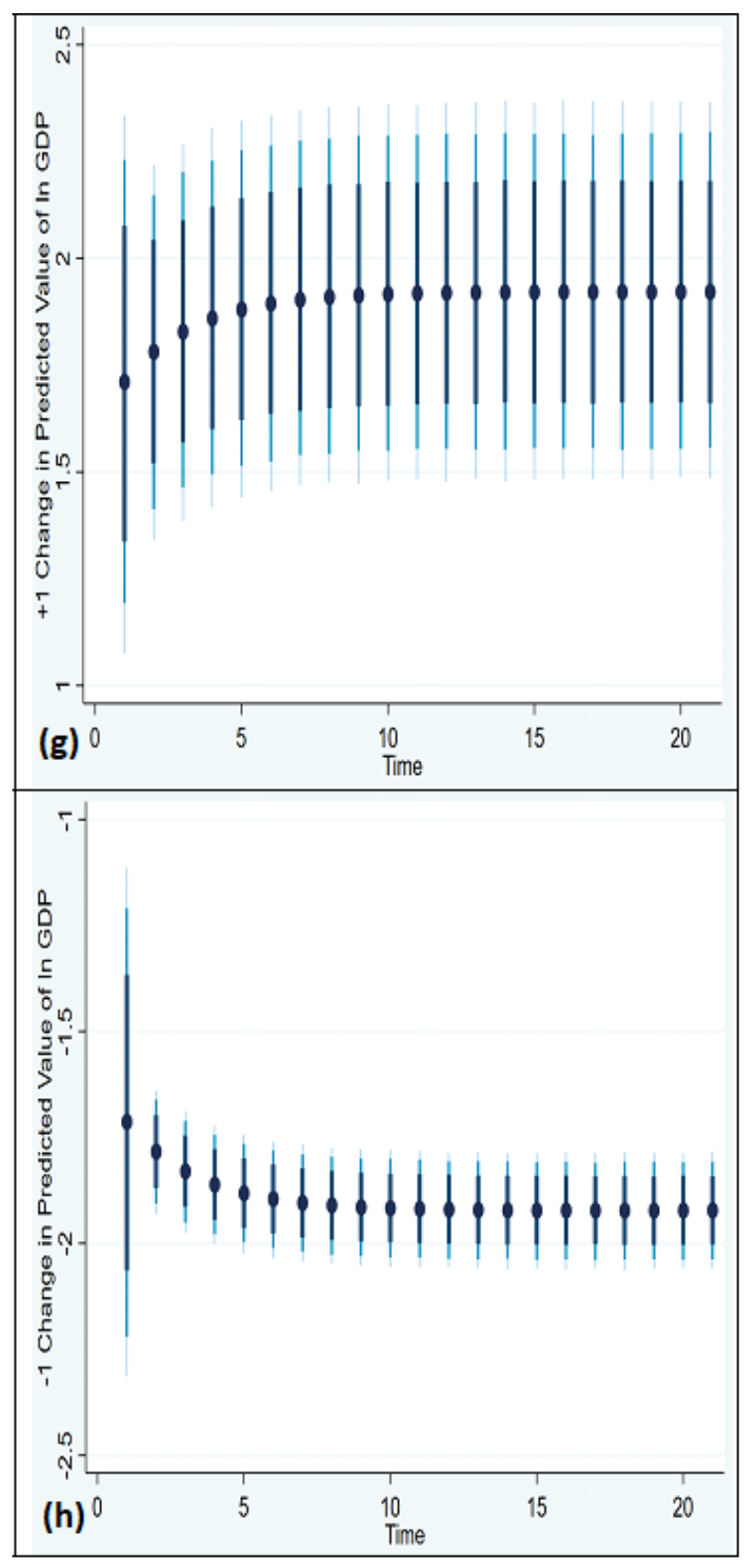

\section{Figure 7}

$( \pm 1 \%)$ alterations in predicted GDP on $\mathrm{CO} 2$ emissions 

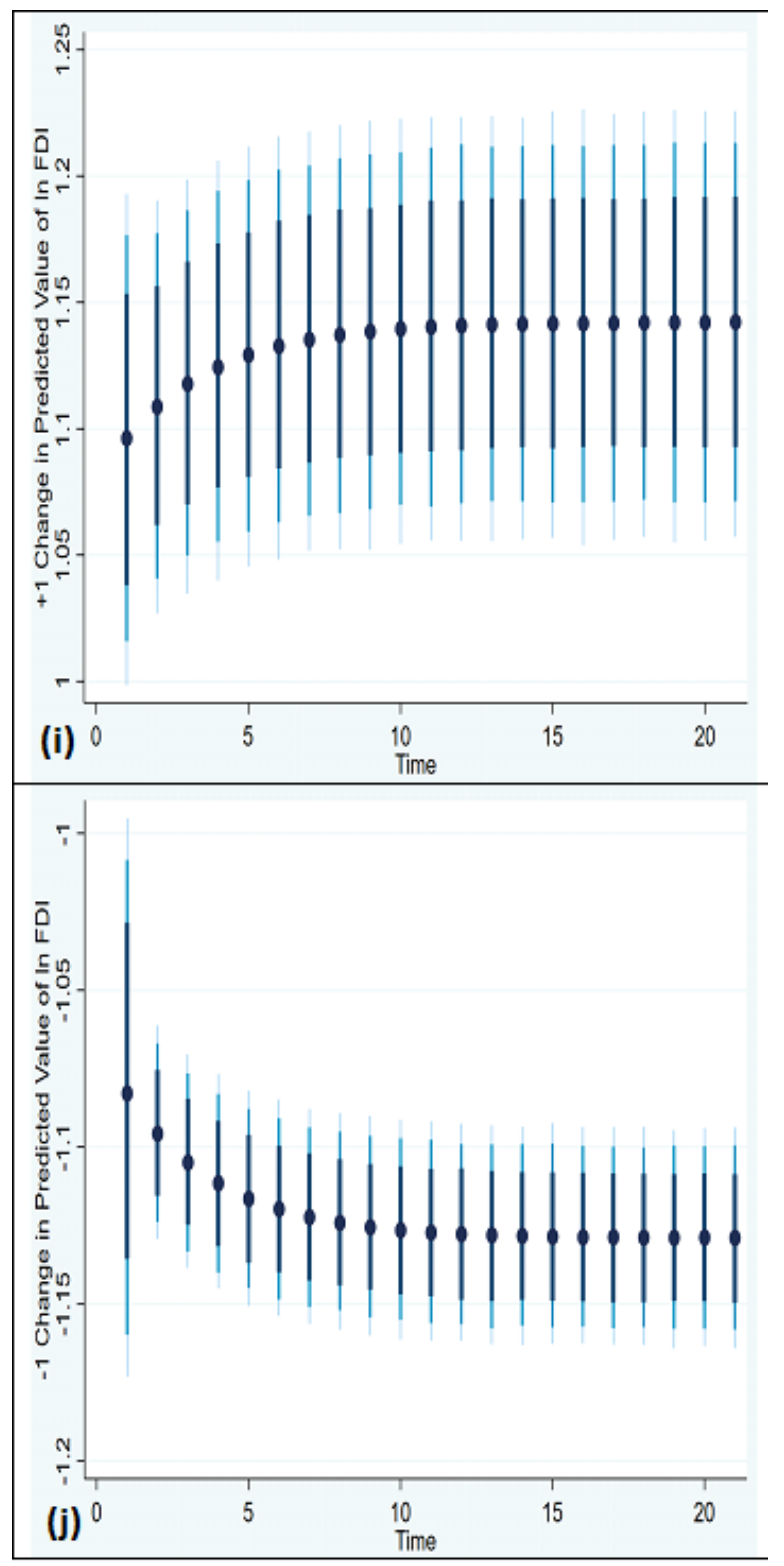

Figure 8

$( \pm 1 \%)$ alterations in predicted FDI on $\mathrm{CO} 2$ emissions 


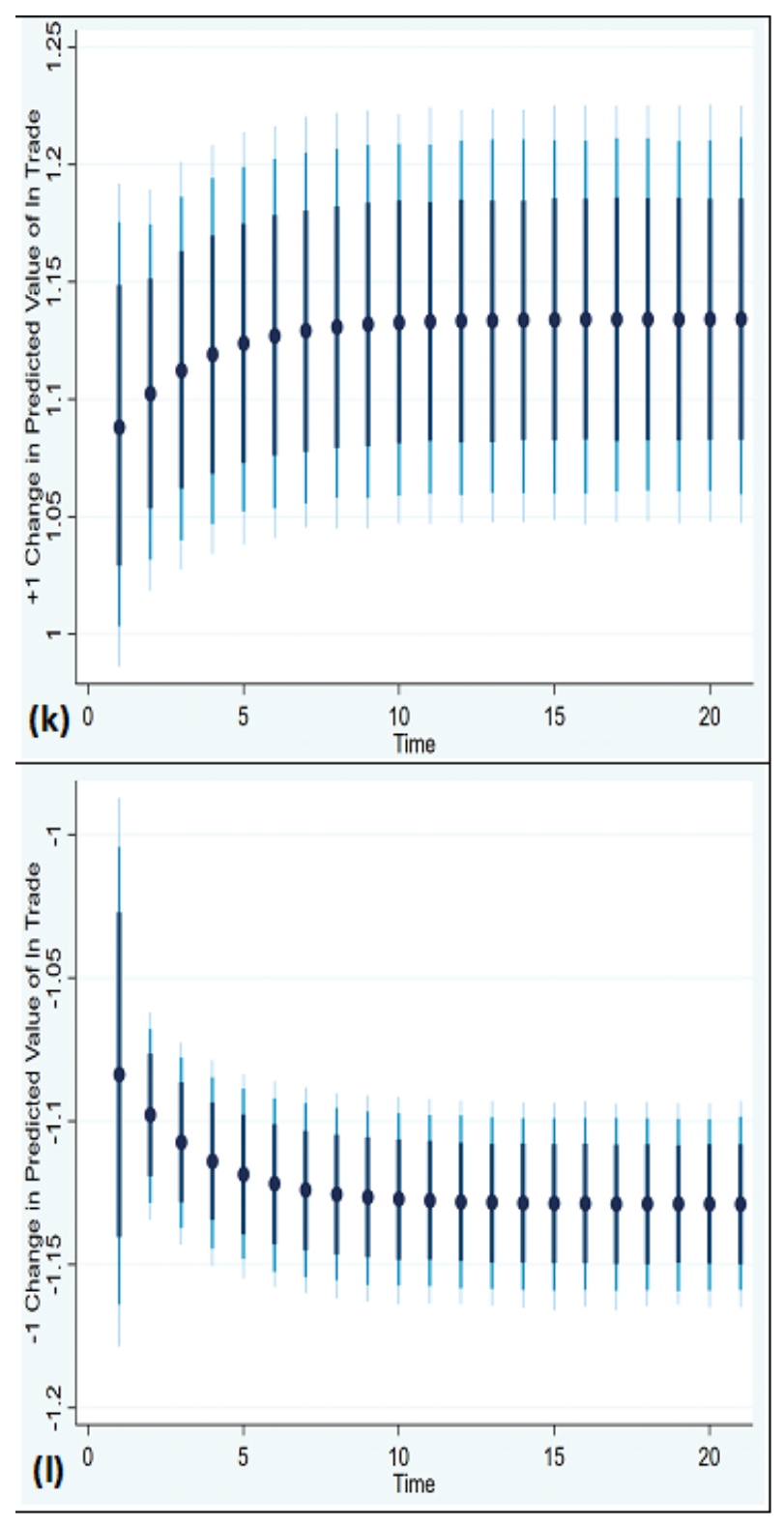

Figure 9

$( \pm 1 \%)$ alterations in predicted Trade on $\mathrm{CO} 2$ emissions 